\title{
Impacto da pandemia na demanda por aplicativo de delivery de alimentação em Piracicaba/SP
}

\author{
Impact of pandemia on demand by food delivery application in Piracicaba/SP \\ Impacto de la pandemia en la demanda por aplicación de entrega de alimentos en Piracicaba/SP
}

Recebido: 10/05/2021 | Revisado: 14/05/2021 | Aceito: 14/05/2021 | Publicado: 30/05/2021

\author{
Gustavo Verdi Menighini \\ ORCID: https://orcid.org/0000-0002-4332-8976 \\ Centro Estadual de Educação Tecnológica Paula Souza, Brasil \\ E-mail: verdimeneghini@gmail.com \\ Jean Carlos Carvalho de Oliveira \\ ORCID: https://orcid.org/0000-0002-9853-2552 \\ Centro Estadual de Educação Tecnológica Paula Souza, Brasil \\ E-mail: jean.oliveira21@ fatec.sp.gov.br \\ Vanessa de Cillos Silva \\ ORCID: https://orcid.org/0000-0002-2844-336X \\ Centro Estadual de Educação Tecnológica Paula Souza, Brasil \\ E-mail: va.csilva@hotmail.com \\ Fabrício José Piacente \\ ORCID: https://orcid.org/0000-0001-8306-4541 \\ Centro Estadual de Educação Tecnológica Paula Souza, Brasil \\ E-mail: fjpiacente@yahoo.com.br
}

\begin{abstract}
Resumo
A chegada da pandemia do Covid-19 no território nacional acarretou medidas de restrição e isolamento, fatores que desencadearam mudanças nos hábitos de consumo da população. Esse trabalho tem como objetivo analisar o aumento na demanda de pedidos de refeições, entre o ano pré-pandêmico e pandêmico (entre 2019 e 2020), em três diferentes restaurantes que fornecem alimentação pronta por meio de entrega (delivery) a partir de um aplicativo de compra, no Município de Piracicaba-SP. O foco é analisar o comportamento da demanda dos pedidos a partir da análise da evolução de três variáveis: i) número de pedidos realizados; ii) faturamento total nos períodos; iii) e ticket médio de compra. Os dados apresentados na pesquisa empírica indicaram um crescimento no número de novos pedidos, no faturamento total e no ticket médio nos três restaurantes analisados, quando comparado os anos de 2019 e 2020 , esse crescimento foi mais evidente no caso do restaurante A.
\end{abstract}

Palavras-chave: Covid-19; Faturamento; Restaurantes; M-commerce.

\begin{abstract}
The arrival of the Covid-19 pandemic in the national territory brought about measures of restriction and isolation, factors that triggered changes in the consumption habits of the population. This work aims to analyze the increase in the demand for meal orders, between the pre-pandemic and pandemic year (between 2019 and 2020), in three different restaurants that provide ready-to-eat food through delivery from an application of purchase, in the Municipality of Piracicaba-SP. The focus is to analyze the demand behavior of orders based on the analysis of the evolution of three variables: i) number of orders placed; ii) total revenue in the periods; iii) and average purchase ticket. The data presented in the empirical research indicated an increase in the number of new orders, in total sales and in the average ticket in the three restaurants analyzed, when compared to the years 2019 and 2020, this growth was more evident in the case of restaurant A.
\end{abstract}

Keywords: Covid-19; Revenues; Restaurants; M-commerce.

\section{Resumen}

La llegada de la pandemia Covid-19 al territorio nacional provocó medidas de restricción y aislamiento, factores que desencadenaron cambios en los hábitos de consumo de la población. Este trabajo tiene como objetivo analizar el aumento de la demanda de pedidos de comida, entre el año prepandémico y pandémico (entre 2019 y 2020), en tres restaurantes diferentes que brindan alimentos listos para consumir a través de delivery desde una aplicación de compra, en el Municipio de Piracicaba-SP. El objetivo es analizar el comportamiento de la demanda de pedidos a partir del análisis de la evolución de tres variables: i) número de pedidos realizados; ii) ingresos totales en los períodos; iii) y ticket de compra medio. Los datos presentados en la investigación empírica indicaron un incremento en el número de nuevos pedidos, en las ventas totales y en el ticket promedio en los tres restaurantes analizados, al 
compararlo con los años 2019 y 2020, este crecimiento fue más evidente en el caso de restaurante A.Incluir o resumo em espanhol.

Palabras clave: Covid-19; Ingresos; Restaurantes; M-commerce.

\section{Introdução}

Hábitos e costumes dos consumidores foram alterados durante o período de pandemia, intensificando o uso da tecnologia. Como pode-se observar, com base em dados fornecidos pela Associação Brasileira de Bares e Restaurantes ABRASEL (2018), o faturamento do mercado de delivery no Brasil cresce a cada ano numa escala anual de pelo menos 1 bilhão de reais. Em 2017, o setor fechou o faturamento em 10 bilhões de reais, registrando um aumento de aproximadamente 1 bilhão de reais em relação ao ano de 2016. Desta forma, torna-se importante analisar como estes tipos de serviços foram atingidos por uma alta na demanda repentina causada pela disseminação do SARs Cov-2 (Novo Coronavírus ou Covid-19).

O aumento no número de usuários deste tipo de serviço já fazia parte do cenário antes mesmo da pandemia, segundo dados da plataforma iFood (2017). No entanto, a intensificação de uso ocorreu durante o cenário atual, que contribuiu para a percepção do funcionamento de um sistema complexo e da sua necessidade dia a dia: pessoas substituíram a ida a supermercados e restaurantes por pedidos em aplicativos de delivery que, por sua vez, oferecem cada vez mais atrativos a seus consumidores, seja pela facilidade em encontrar produtos com descontos ou pela comodidade em receber em casa, com o mínimo contato externo.

Em consequência, a limitação de oferta de produtos e serviços ocasionada pela conjuntura atual levou a todos os agentes sociais e econômicos (indivíduos, empresas e governos) a modificarem seu comportamento de consumo.

Rezende et al. (2020) afirmam que, no atual contexto, o consumidor, em particular os indivíduos que são os usuários principais do processo econômico e de manutenção do fluxo comercial e financeiro, tendem a mudar seu comportamento perante situações adversas, principalmente aquelas que atentam contra sua vida, que é o caso desta pandemia.

Esse trabalho tem o objetivo de analisar o aumento na demanda de pedidos de refeições, entre o ano pré-pandêmico e pandêmico (entre 2019 e 2020), em três diferentes restaurantes que fornecem alimentação pronta por meio de entrega (delivery) por meio de um aplicativo de compra. Os restaurantes apresentam especialidades gastronômicas distintas, sendo: uma churrascaria; um restaurante de gastronomia japonesa; e o último classificado como de gastronomia brasileira. Esses estabelecimentos estão localizados no Município de Piracicaba-SP e utilizaram-se do serviço do mesmo aplicativo de pedido e entrega durante o período de análise. O foco é analisar o comportamento da demanda dos pedidos realizados através de um aplicativo específico, a partir da análise da evolução de três variáveis: i) número de pedidos realizados; ii) faturamento total nos períodos; iii) e ticket médio de compra.

\section{Referencial Teórico}

\subsection{Crescimento das Compras por Meio de Aplicativos}

Nos dias atuais os consumidores prezam por fatores como praticidade, comodidade e rapidez. Tais fatores maximizam o uso do comércio eletrônico realizado a partir de aplicativos em aparelhos móveis, chamado mobile commerce ou simplesmente m-commerce. Lemos e Góes (2015) destacam que o desenvolvimento do m-commerce, que pode ser definido como o comércio eletrônico realizado em dispositivos móveis, ocorreu juntamente com o aumento da velocidade da internet e a praticidade em acessá-la em qualquer lugar.

Steendern (2002) elucida que a procura por mobilidade impulsionou o $\mathrm{m}$-commerce, trazendo a possibilidade de fazer compras de qualquer lugar por meio digital. Trata-se de uma das mais recentes e importantes mudanças no ambiente de negócios, o que significa uma melhor capacidade de acessar recursos de informação e serviços em qualquer lugar. Neste contexto, o conceito de mobile commerce (m-commerce), pode ser classificado como uma variante do comércio eletrônico (e- 
commerce).

Segundo Torres (2009), novos aparelhos celulares, e a tecnologia 3G permitiu ganhos na comunicação móvel, e com a convergência a Internet passou a fazer parte desse universo móvel. Alguns especialistas se apressaram em criar mais um nome para o já saturado mercado de jargões tecnológicos: o mobile marketing. Para o autor, o comércio virtual proporciona facilidades na hora de realizar compras. Além da vantagem de escolher e receber o produto diretamente em casa, sem enfrentar trânsitos e filas, as compras online ganham inúmeras formas de pagamentos e evitam o risco de obter um mau atendimento de profissionais despreparados.

Geraldo e Mainardes (2017) explicam que os ambientes digitais proporcionam melhorias como ciclos de vendas mais curtos, redução de custos, melhoria no atendimento e qualidade dos serviços. Logo, é possível extrair informações relevantes como as intenções de compra dos consumidores, caracterizando os fatores ansiedade, facilidade de uso, utilidade e preço como determinantes para a decisão da compra. Com o comércio online, o varejo possibilita a expansão ilimitada de oferta de produtos e serviços. Logo, o consumidor se beneficia com personalização do produto, comunicação interativa e entrega rápida. Apesar da indústria de alimentos ser um mercado saturado, os varejistas começaram a fornecer serviços online adicionais para permanecerem competitivos.

\subsection{Aplicativos de Delivery para Restaurantes}

O conceito de delivery traz o significado da palavra em inglês que pode ser traduzida como: entrega, distribuição ou remessa. Trata-se de um serviço de entrega de materiais, bens, serviços ou produtos a um determinado lugar, solicitados através de algum meio de comunicação. Entre os itens que fazem parte, atualmente, dos serviços de delivery, estão medicamentos, bebidas e produtos de supermercados (Sebrae, 2005).

Os desafios e oportunidades dos serviços de alimentação surgem conforme a sociedade ganha novos estilos de vida que, por sua vez, modificam hábitos alimentares. O modo de vida urbano corriqueiro tem ocasionado mudanças nos hábitos alimentares das pessoas. Em somatório, uma facilidade moderna acompanha este impulso: os aplicativos de delivery. Enquanto há alguns anos, os pais iriam pedir uma pizza por telefone presente em uma lista junto com vários outros telefones, hoje os jovens têm a comodidade em diversas opções de cardápios na tela de seus celulares para solicitar sua refeição e degustá-la na própria residência (Abrasel, 2018).

Desde então, as profissões de motorista e entregador se reinventaram por meio dos aplicativos. São mais de 600 mil pessoas cadastradas como motoristas do Uber no país. Incluem ainda, os entregadores de bicicletas e motos de aplicativos de entrega como iFood, UberEats, Loggi e Rappi. Em 2019, na cidade de São Paulo, havia aproximadamente 60 mil entregadores e 150 mil motoristas na Uber, totalizando 2,4\% da mão de obra da cidade (Ortellado, 2019).

Com a entrada dos aplicativos de delivery, houve uma expansão no mercado de entrega de comidas. De acordo com a Associação Brasileira de Bares e Restaurantes - ABRASEL (2018), o mercado de delivery para o setor tem apresentado um crescimento anual médio de $12 \%$. O aumento anual em seu faturamento chega a R \$ 1 bilhão, e em 2017, o setor fechou o faturamento em 10 bilhões de reais. Além de lucrativo, os serviços de delivery com auxílio de aplicativos mobile oferecem maior comodidade e praticidade na hora de solicitar o serviço de entrega, pois pode ser acessado de qualquer lugar.

Segundo iFood (2017), a história da startup começou em 2011, quando os então sócios do Disk Cook, fundado em 1997, resolveram passar do atendimento via telefone para o mundo digital. Desde então, a empresa vem recebendo investimentos de novos sócios, como a Warehouse, Movile e Just Eat, o que tem possibilitado a sua expansão, de aproximadamente $8.000 \%$ em três anos. A compra de empresas regionais semelhantes, como Papa Rango em São José do Rio Perto (SP), assim como a fusão com o Restaurante Web, em 2014, alavancou a liderança no mercado nacional. Atualmente, a 
plataforma atende 20 milhões de pedidos mensais. No Brasil, destacam-se outros aplicativos, como o PedidosJá, da alemã Delivery Hero; HelloFood, do fundo de investimento alemão Rocket Internet que é operado pelo iFood no Brasil desde 2016.

Segundo Iodice (2019), o Brasil é o maior mercado de entrega de comida da América Latina. A busca por conveniência, conforto, economia de tempo e segurança são alguns dos fatores e fortalece o mercado o surgimento de aplicativos que tornam a vida do consumidor e do restaurante ainda mais fáceis. Segundo a autora, em outubro de 2017, o iFood, principal empresa do setor de delivery alimentício atuando no país, alcançou 5 milhões de usuários ativos na plataforma, 6,2 milhões de pedidos mensais na América Latina e fechou o ano de 2017com 180\% de crescimento.

Segundo Consumer (2017) a utilização de serviços do tipo delivery demanda inicialmente do empresário um aumento no gasto com investimento. Deve-se observar que a tendência é um crescimento na demanda dos produtos e serviços, o que poderá comprometer o atendimento físico de instalações não adaptadas para esse tipo de serviço, aumentando principalmente o tempo de atendimento. Assim, investimentos em estrutura física dos restaurantes, a contratação de novos funcionários e o treinamento da equipe, são condições fundamentais para o empresário que resolva atuar com esse tipo de plataforma online. Outro ponto analisado são os impactos do distanciamento entre os clientes e o empresário, de maneira geral, os serviços de vendas online não permitem uma relação direta entre esses dois agentes, impedindo que o empresário tenha informações sobre o perfil e a satisfação da sua base de clientes, dificultando ações que visem a melhoria nos produtos e do serviço de entrega. Adiciona-se a esses pontos dificuldades como a falta de uma boa conectividade com a internet; os custos para manter a parceria com o operador da plataforma; a concorrência acirrada; e um layout padronizado, já que vários estabelecimentos compartilham o mesmo espaço dentro do aplicativo.

\subsection{O Impacto da Pandemia no Uso de Aplicativos}

A humanidade enfrenta um dos piores momentos de sua história. Com a disseminação do SARs Cov-2 (Novo Coronavírus ou Covid-19) em escala mundial, as expectativas de crescimento no Brasil e no mundo foram substituídas por um cenário extremamente apreensivo com a economia mundial em um processo de recessão (Matos \& Miranda, 2020).

A chegada da pandemia no país agravou o quadro de crise social e econômica do país. Os impactos sobre a população e o mercado de trabalho acarretaram aumento do desemprego, redução da renda, desestruturação de pequenas atividades e fechamento de empresas no país. Com a tomada de medidas de restrição a partir de março de 2020, houve mais de 7,8 milhões de desempregados, sendo que 5,8 milhões representam o "setor informal". Ainda, houve o fechamento de 1,4 milhão de postos de trabalho formais, dos quais 331,9 mil são apenas no mês de maio de 2020 (Máximo, 2020).

No cenário atual de pandemia do Novo Coronavírus, além de ganhar maior visibilidade, entregadores de aplicativos também assumiram um papel vital de garantia do funcionamento da economia urbana ao realizarem o abastecimento da população, através de entregas de supermercados, restaurantes, farmácias etc.

Conforme Abílio (2020), a necessidade da população em ser atendida em suas casas, mostrou as diferenças sociais entre aqueles que tiveram o privilégio do isolamento domiciliar e aos que tiveram que se arriscar para sobreviver. Graças à mobilidade e conectividade provenientes do uso dos smartphones, seus usuários passam a ser integrantes de um sistema conhecido como economia do compartilhamento, que tem como exemplo novas formas de "empreendedorismo" e "parcerias" junto às empresas de aplicativos.

A pandemia do Covid-19 no território brasileiro, iniciou-se no mesmo período do auge da expansão das plataformas digitais e dos aplicativos de m-commerce pelo país. O contexto de isolamento residencial tem favorecido o aumento nos acessos nas diferentes plataformas digitais para entregas. Os serviços de entrega foram classificados como atividades essenciais desde o primeiro momento da quarentena, de acordo com Art. 3 do Decreto $n^{\circ}$ 10.282, de 20 de março de 2020 (Brasil, 2020). 
De acordo com Montenegro (2020), o aumento na aceitação destes tipos de aplicativos ocorreu em abril de 2020, alcançando a marca de presença em 22 milhões de aparelhos celulares no país. Na América Latina, a empresa de m-commerce Rappi obteve um crescimento de mais de 30\% em seu volume de entrega apenas no mês de abril de 2020.

Segundo Marino (2020), a plataforma iFood anunciou que obteve a marca de 39 milhões em pedidos no mês de março de 2020. Atualmente essa plataforma de aplicativo de delivery conta com mais de 236 mil restaurantes parceiros, estando presente em mais de 1.000 cidades do país.

\section{Metodologia}

O presente trabalho é baseado em uma pesquisa bibliográfica, de características quantitativas e com coleta de dados primários a partir de uma amostragem por conveniência. Segundo Marconi e Lakatos (2003), Gil (2019) e Severino (2016), a pesquisa bibliográfica é o levantamento de bibliografias já publicadas em relação ao tema em estudo, tais como: revistas, livros, boletins e jornais, com finalidade de auxiliar na análise da pesquisa. Os dados primários apresentam abordagem quantitativa, ou seja, foram coletados dados numéricos que podem ser analisados por técnicas matemáticas (Pereira et al., 2018).

Com a finalidade de atingir o objetivo proposto inicialmente nessa pesquisa foram coletados, dos restaurantes selecionados, dados primários quanto à evolução de três variáveis: i) número de pedidos realizados; ii) faturamento total nos períodos; iii) e ticket médio de compra. Esses dados referem-se a um determinado aplicativo de delivery, convenientemente escolhido para a pesquisa por apresentar abrangência espacial relevante na cidade de Piracicaba-SP. A cidade foi escolhida devido a sua população estimada - equivalente a 407.252 pessoas - sendo a $16^{\circ}$ maior cidade do Estado de São Paulo, segundo dados do IBGE (2020).

O período em questão para coleta e análise dados foram os anos de 2019 (ano que antecedeu a pandemia) e 2020 (ano pandêmico), com o objetivo que apresentar uma análise relativa dos impactos causado pela pandemia, isolamento social e recomendações dos órgãos de saúde na demanda por pedidos de refeições, em três diferentes restaurantes que fornecem alimentação pronta por meio de entrega (delivery) através de um aplicativo de compra

Por questões de confidencialidade, o nome do aplicativo de delivery e dos restaurantes pesquisados neste estudo serão mantidos em sigilo. Quanto aos restaurantes, foram escolhidos em função do seu porte; tipos de gastronomia: (i) Restaurante A: gastronomia japonesa; ii) Restaurante B: churrascaria; iii) Restaurante C: comida brasileira; capacidade de atendimento; localização privilegiada próxima a região central da cidade; e disponibilidade do atendimento por aplicativos de delivery. Quanto ao público-alvo de cada um dos restaurantes selecionados, o restaurante A destina seus serviços e produtos a um grupo enquadrado socialmente como classe "A"; o restaurante B volta-se a um grupo misto de classe social "A" e "B"; e o restaurante $\mathrm{C}$ voltado predominantemente para a classe " $\mathrm{C}$ ".

\section{Resultados e Discussão}

\subsection{Restaurante A}

O restaurante A, que atua com gastronomia japonesa, apresentou aumento no número de pedidos nos meses de 2020 se comparados ao mesmo período em 2019. O Gráfico 1 traz a evolução no número de pedidos mensais realizados pelo aplicativo em estudo nos anos de 2019 e 2020 para o caso do restaurante A. Observa-se que o número de pedidos total para o ano de 2019 foi de 5.033 e em 2020 foi de 13.590, um crescimento de mais de 170\%, o que representa uma evolução média de mais de $15 \%$ ao mês durante o período analisado. 
Gráfico 1 - Número de pedidos mensais realizados por um aplicativo de delivery no restaurante A nos anos de 2019 a 2020.

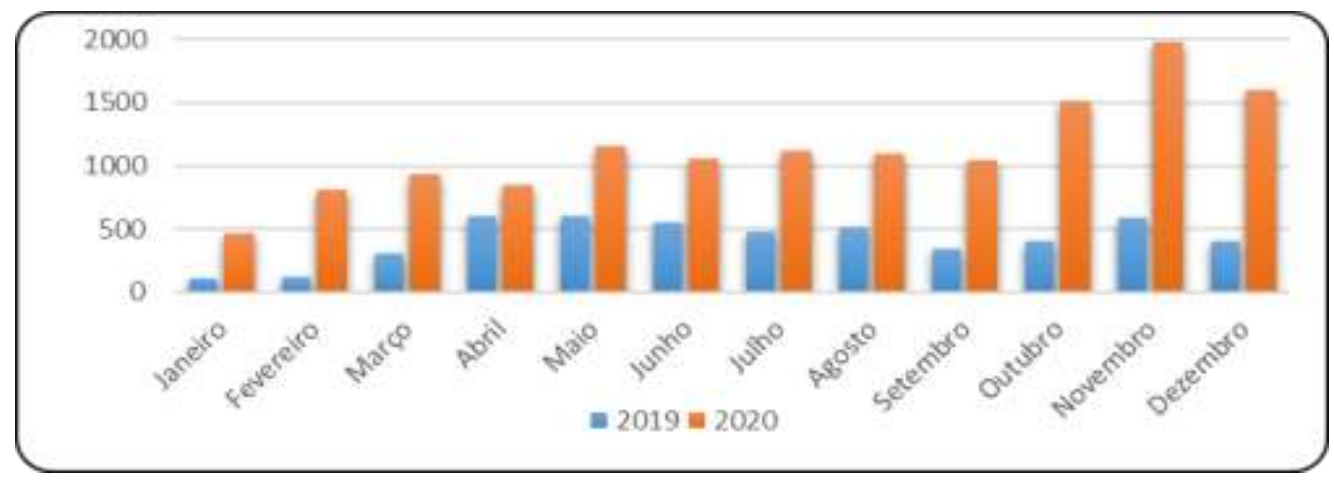

Fonte: Elaborado pelos autores com base nos dados da pesquisa

Após decretada a pandemia no Brasil (em meados de março de 2020), os meses de março, setembro outubro, novembro e dezembro se destacaram com aumentos médios superiores a $200 \%$ no número de pedidos, quando comparados ao mesmo período em 2019.

Em relação a variável faturamento mensal, conforme pode ser visualizado no Gráfico 2, nota-se que o faturamento do restaurante A através da utilização do aplicativo em estudo foi de $\mathrm{R} \$ 202.818,09$ para o ano de 2019 e de $\mathrm{R} \$ 820.817,33$ em 2020, um aumento de mais de $300 \%$, o que representa uma evolução média de aproximadamente $27,7 \%$ ao mês durante o período analisado.

Gráfico 2 - Faturamento mensal referente aos pedidos realizados por um aplicativo de delivery no restaurante A nos anos de 2019 a 2020.

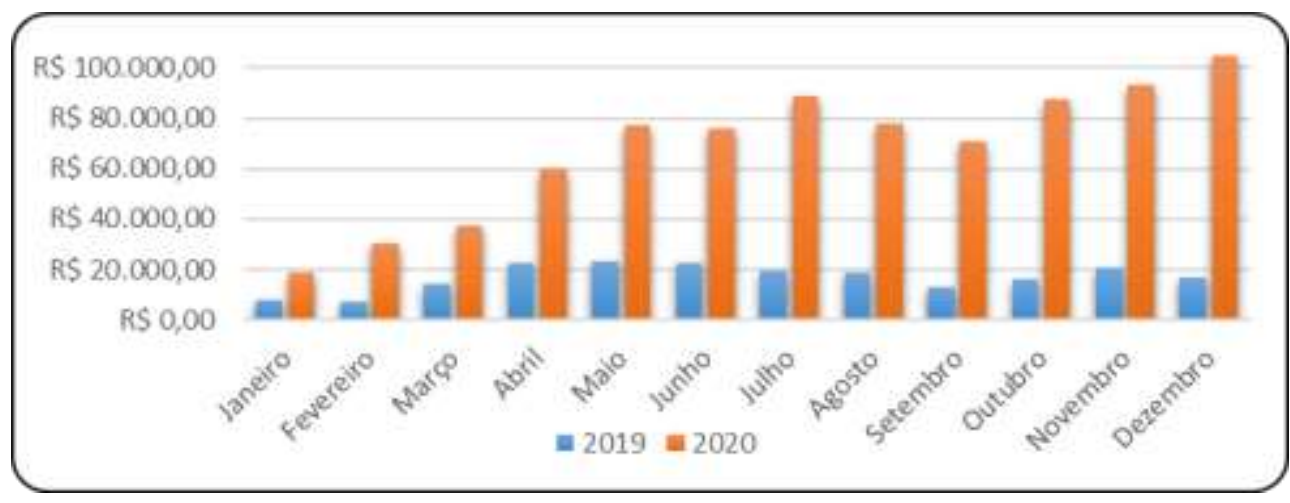

Fonte: Elaborado pelos autores com base nos dados da pesquisa.

Em todos os meses analisados observa-se aumento no faturamento no ano de 2020 quando comparado a 2019. Porém, nos meses compreendidos entre de julho e dezembro de 2020, período de pandemia, a evolução no faturamento foi superior a $300 \%$, quando comparados ao mesmo período de 2019. O destaque foi o mês de dezembro, que em 2019 apresentou um faturamento de $\mathrm{R} \$ 16.805,10$ e em 2020 esse valor foi de $\mathrm{R} \$ 104.563,12$, ou seja, crescimento de aproximadamente $522 \%$.

O Gráfico 3 ilustra dados referentes ao comparativo entre o ticket médio mensal do restaurante A nos anos de 2019 e 2020. O ticket médio é calculado dividindo-se o faturamento pelo número de pedidos. Nota-se que, de maneira geral, o ticket médio teve um aumento de $35,4 \%$, o que nos remete uma taxa média de crescimento de aproximadamente $3,4 \%$ ao mês. 
Gráfico 3 - Ticket médio mensal referente aos pedidos realizados por um aplicativo de delivery no restaurante A nos anos de 2019 a 2020.

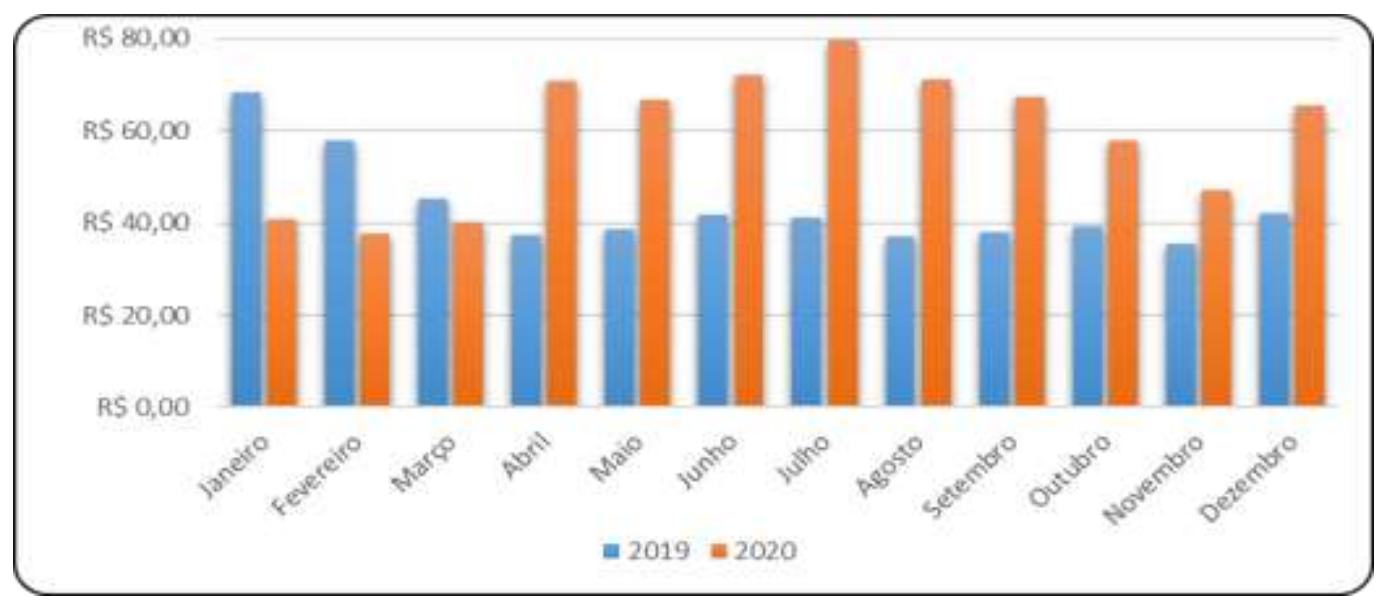

Fonte: Elaborado pelos autores com base nos dados da pesquisa.

Constata-se que nos três primeiros meses de 2020 o valor do ticket médio foi inferior se comparado ao mesmo período do ano de 2019. Isso ocorreu em virtude da taxa de crescimento do número de pedidos ter superado o percentual de crescimento do faturamento. Os meses de abril, julho e agosto foram os que apresentaram maiores aumentos em 2020 quando comparados ao mesmo mês de 2019, valores mensais médios próximos a $92 \%$ de crescimento.

\subsection{Restaurante B}

O restaurante B, caracterizado como churrascaria, apresentou aumento no número de pedidos nos meses de 2020 se comparados ao mesmo período em 2019. O Gráfico 4 apresenta a evolução mensal no número de pedidos do restaurante B realizados pelo aplicativo em estudo entre os anos de 2019 e 2020. Observa-se que o número de pedidos total para o ano de 2019 foi de 32.052 e em 2020 foi de 57.014, uma variação percentual entre os dois anos analisados de aproximadamente 78\%, o que representa uma evolução média $7 \%$ ao mês.

Gráfico 4 - Número de pedidos mensais realizados por um aplicativo de delivery no restaurante B nos anos de 2019 a 2020.

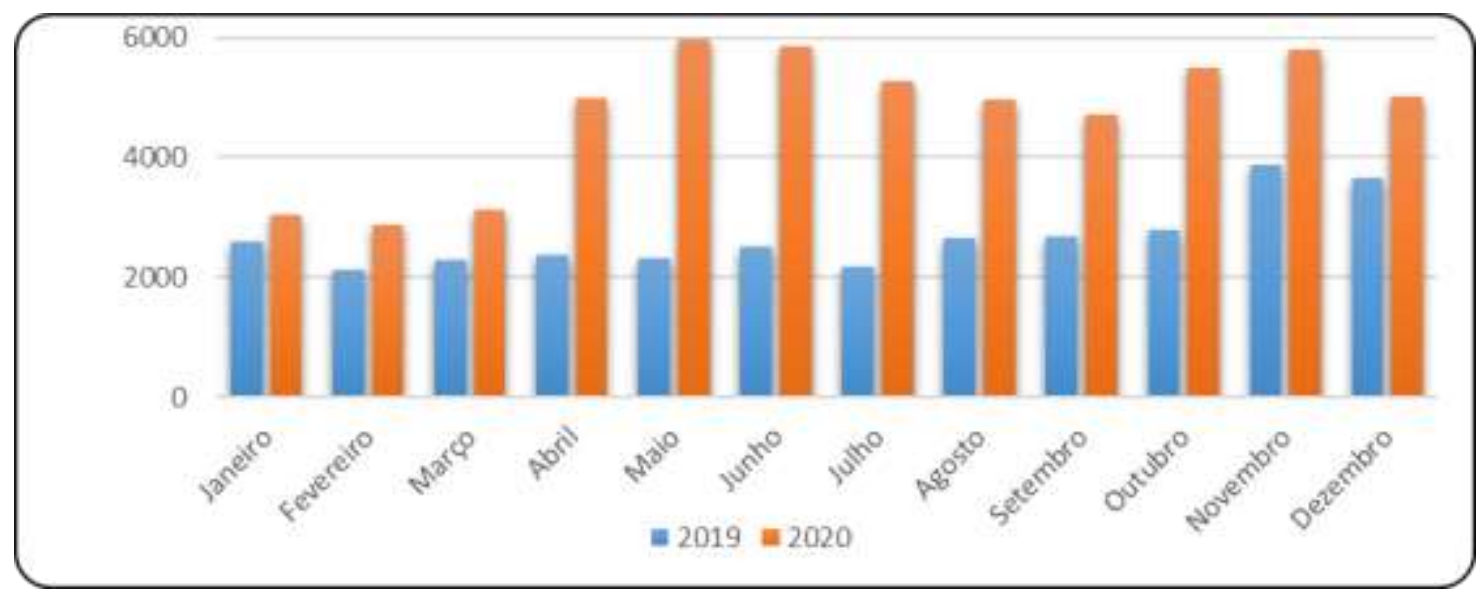

Fonte: Elaborado pelos autores com base nos dados da pesquisa. 
Entre os meses analisados, destacam-se os meses de abril, maio, junho e julho de 2020, cujas taxas de crescimento, quando comparadas com os mesmos meses de 2019, foram de aproximadamente $109 \%, 156 \%$, $132 \%$ e $142 \%$, respectivamente. Esses meses coincidem com o início da pandemia no Brasil, que foi decretada em março de 2020.

Quanto aos dados de faturamento mensal, conforme pode ser visualizado no Gráfico 5, nota-se que o faturamento do restaurante B pelo aplicativo, foi de $\mathrm{R} \$ 1.044 .078,80$ para o ano de 2019 e de $\mathrm{R} \$ 2.443 .880,71$ em 2020 , uma variação percentual anual de aproximadamente 134\%, o que representa uma evolução média mensal de 12,2\% durante os períodos analisados.

Gráfico 5 - Faturamento mensal referente aos pedidos realizados por um aplicativo de delivery no restaurante B nos anos de 2019 a 2020.

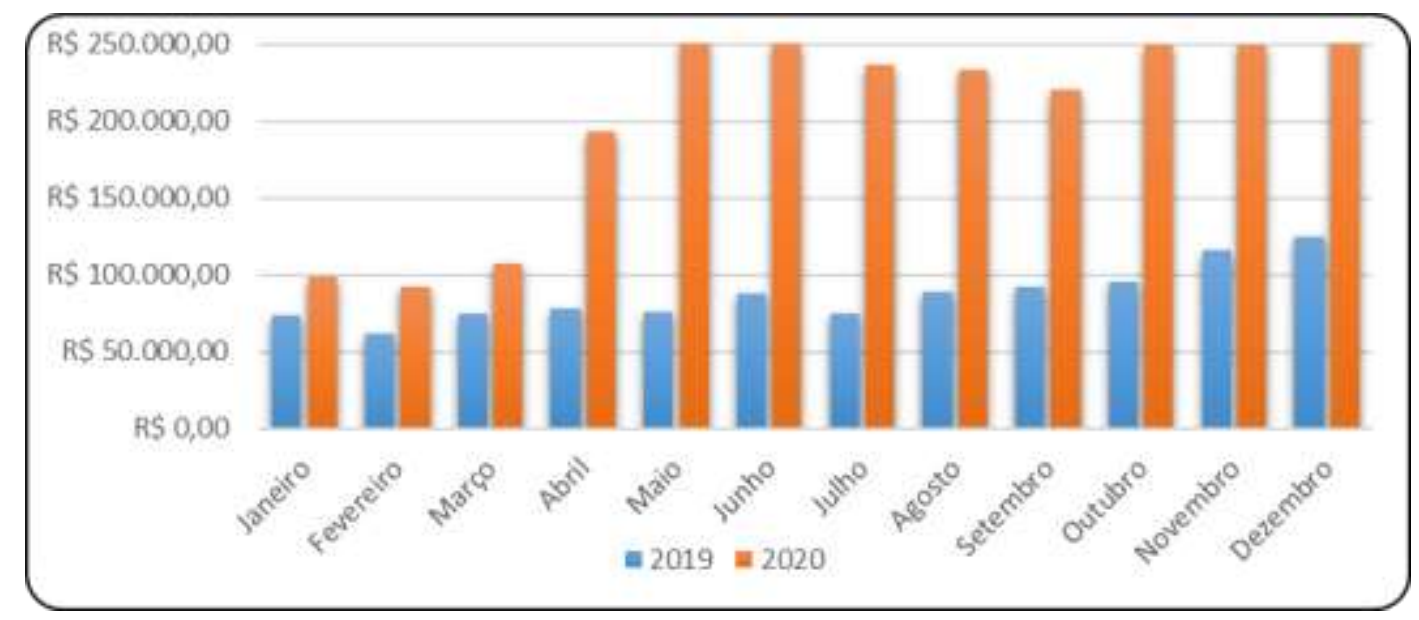

Fonte: Elaborado pelos autores com base nos dados da pesquisa.

Em todos os meses analisados observa-se aumento no faturamento no ano de 2020 quando comparado a 2019. Porém, nos meses compreendidos entre de abril e dezembro de 2020, período compreendido na pandemia, a evolução no faturamento foi superior a $100 \%$ quando comparados ao mesmo período de 2019 . O destaque é para o mês de maio, que em 2019 apresentou um faturamento de $\mathrm{R} \$ 76.391,49$ e em 2020 esse valor passou para $\mathrm{R} \$ 253.151,48$, ou seja, crescimento de aproximadamente $231 \%$.

O Gráfico 6 ilustra dados referentes ao comparativo entre o ticket médio mensal do restaurante B nos anos de 2019 e 2020. Nota-se que, de maneira geral, o ticket médio teve um aumento de $28,5 \%$, o que nos remete uma taxa média de crescimento de aproximadamente 2,6\% ao mês. Em todo o período analisado, o crescimento mensal no faturamento foi superior ao do número de pedidos, o que gerou aumento em todos os meses de 2020 quando comparados a 2019. 
Gráfico 6 - Ticket médio mensal referente aos pedidos realizados por um aplicativo de delivery no restaurante A nos anos de 2019 a 2020.



Fonte: Elaborado pelos autores com base nos dados da pesquisa.

De acordo com os dados do Gráfico 6, as taxas de ticket médio destacaram-se positivamente entre os meses de julho a dezembro, apresentando crescimentos mensais médios superiores a 39\%. O mês de dezembro foi o que apresentou maior crescimento passando de $\mathrm{R} \$ 34,04$ em 2019 para $\mathrm{R} \$ 51,32$ em 2020, aumento de 50,8\%.

\subsection{Restaurante C}

O restaurante $\mathrm{C}$, classificado como de comida brasileira, apresentou aumento no número de pedidos nos meses de 2020, quando comparados ao mesmo período em 2019. O Gráfico 7 apresenta a evolução no número de pedidos mensais realizados pelo aplicativo em estudo nos anos de 2019 e 2020. Observa-se que o número de pedidos total para o ano de 2019 foi de 16.776 e em 2020 foi de 30.911, um aumento de aproximadamente de $84 \%$, o que representa um crescimento médio de $7,7 \%$ ao mês durante o período analisado. Entre os meses analisados, destacam-se os de fevereiro, março, abril e dezembro, cujas taxas de crescimento foram superiores a 100\% em relação ao mesmo período no ano de 2019.

Gráfico 7 - Número de pedidos mensais realizados por um aplicativo de delivery no restaurante C nos anos de 2019 a 2020.

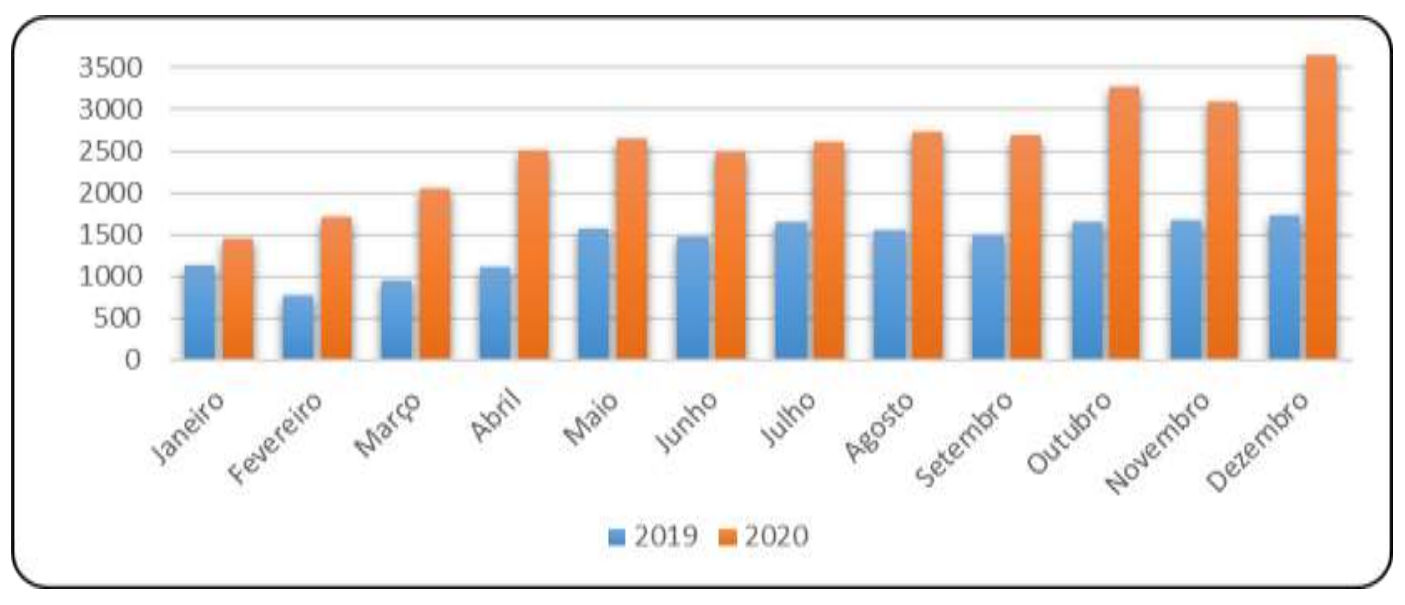

Fonte: Elaborado pelos autores com base nos dados da pesquisa. 
Em relação a variável faturamento mensal, conforme pode ser visualizado no Gráfico 8, nota-se que o faturamento total do restaurante $\mathrm{C}$ pelo aplicativo em estudo foi de $\mathrm{R} \$ 345.489,00$ para o ano de 2019 e de $\mathrm{R} \$ 763.526,21$ em 2020, um aumento de aproximadamente $121 \%$, o que representa uma evolução média de $11 \%$ ao mês durante o período analisado.

Gráfico 8 - Faturamento mensal referente aos pedidos realizados por um aplicativo de delivery no restaurante A nos anos de 2019 a 2020.



Fonte: Elaborado pelos autores com base nos dados da pesquisa.

Em todos os meses analisados observa-se aumento no faturamento no ano de 2020 quando comparado a 2019. No período de fevereiro a dezembro de 2020 a evolução no faturamento foi superior a $100 \%$ quando comparados ao mesmo período de 2019. O destaque é para o mês de abril, que em 2019 apresentou um faturamento de R $\$ 23.142,50$ e em 2020 esse valor passou para $\mathrm{R} \$ 63.515,75$, ou seja, crescimento de aproximadamente $174 \%$. O mês de abril de 2020 é o mês subsequente ao início da pandemia no Brasil.

O Gráfico 9 ilustra dados referentes ao comparativo entre o ticket médio mensal do restaurante C nos anos de 2019 e 2020. Nota-se que, de maneira geral, o ticket médio teve um aumento de $19 \%$, o que nos remete uma taxa média de crescimento de aproximadamente $1,7 \%$ ao mês. Em todo o período analisado, o crescimento mensal no faturamento foi superior ao do número de pedidos, o que gerou aumento em todos os meses de 2020 quando comparados a 2019. 
Gráfico 9 - Ticket médio mensal referente aos pedidos realizados por um aplicativo de delivery no restaurante A nos anos de 2019 a 2020.



Fonte: Elaborado pelos autores com base nos dados da pesquisa.

De acordo com os dados apresentados, os meses de abril a agosto e novembro destacam-se quanto as taxas de crescimento de ticket médio mensais, apresentando valores superiores a $20 \%$. O mês de maio foi o que apresentou maior crescimento passando de $\mathrm{R} \$ 20,62$ em 2019 para $\mathrm{R} \$ 26,69$ em 2020, aumento de 29,4\%.

\section{Considerações Finais}

A chegada da pandemia do Covid-19 potencializou a consolidação dos diversos aplicativos de entregas pela sociedade em geral. O serviço tornou-se fundamental para que os restaurantes adaptassem seus serviços de alimentação nas novas condições sanitárias ocasionadas pelas diretrizes da pandemia. Parte dos consumidores, impossibilitados de frequentarem presencialmente os restaurantes, optaram pela praticidade dos aplicativos de $m$-commerce, em especial os de delivery de alimentação, o que tem potencializado a demanda desse tipo de serviço nos estabelecimentos analisados.

Os dados apresentados na pesquisa empírica, de maneira geral, indicam um crescimento no número de novos pedidos, no faturamento total e no ticket médio nos três restaurantes analisados, quando comparado os anos de 2019 e 2020 . Esse crescimento é mais evidente, no caso do restaurante A, em relação aos demais.

Os meses de abril e maio apresentaram as maiores variações percentuais mensais para o ano de 2020 quando analisadas as variáveis número de pedidos e faturamento, indicando um impacto positivos das medidas de restrições na opção de $m$-commerce para delivery de alimentação na amostra estudada.

Apesar do estudo não considerar os impactos de todas as datas sazonais para o setor de restaurantes, nem estratégias de marketing localizadas ou individualizadas por estabelecimento, observou-se na amostra que os restaurantes em conjunto com a própria plataforma utilizaram especificamente dois meses como datas para atrair novos clientes com promoções: em março o "Dia do Consumidor"; e em novembro a "Black Friday". Os dados apresentados não puderam indicar uma substancial alteração nas variáveis quando analisado os números para o mês de março.

No caso do mês de novembro, nota-se um aumento expressivo no número de pedidos realizados em 2020 e 2019 nos dados coletados dos restaurantes A e B. Para o restaurante A, o mês de novembro foi o que apresentou maior número de pedidos no ano de 2020. Em outubro de 2020 esse valor foi de 1.514 pedidos, em novembro do mesmo ano foi de 1.978 , uma variação percentual de mais de 30,6\%. Em dezembro foi de 1.596, quando comparado com novembro, uma redução de $19,3 \%$. Para os mesmos períodos de 2019, observa-se um desempenho comparativo melhor no número de pedidos, que variou 
positivamente entre outubro e novembro em 45,3\% e reduziu entre novembro e dezembro aproximadamente 32,5\%. Para o caso do restaurante B, esse aumento no número de pedidos entre outubro e novembro de 2020 foi de apenas 5,6\% e entre novembro e dezembro, uma redução de 13,7\%. Em 2019, esses valores calculados foram de 38,2\% e $-5,1 \%$, respectivamente. Para o restaurante $C$ não foi notada essa tendência. Assim, constata-se um crescimento pontual no número de pedidos para o mês de novembro, quando comparado com os meses de outubro e dezembro, para os restaurantes A e B. Segundo informaç̃es dos administrados dos restaurantes A e B esse desempenho no número de pedidos nos meses de novembro foi explicado, em partes, em função das campanhas de marketing da Black Friday.

Por fim, pode-se apontar como estudos futuros realizar pesquisas que estimem através de modelos estatísticos econométricos o comportamento da demanda pelos serviços de delivery pelo $m$-commerce de alimentação considerando novas variáveis, tais como: perfil de consumidores; características estruturais de estabelecimentos; faturamentos de atendimento presencial, entre outros.

\section{Referências}

Abílio, L. (2020). Uberização e viração: Mulheres Periféricas no Centro da Acumulação Capitalista. 31, 54-61: Revista Margem Esquerda.

Abrasel. (2018). Associação Brasileira de Bares e Restaurantes - O Mercado de Delivery de Comida Fatura Mais de 10 bilhões no Brasil. http://www.sp.abrasel.com.br/noticias/4410-27022018-mercado-de-delivery-de-alimentos-fatura-mais-de-r10-bi-no-brasil

Brasil (2020). Decreto $n^{\circ} 10.282$, de 20 de março de 2020. Regulamenta a Lei $\mathrm{n}^{\mathrm{o}} 13.979$, de 6 de fevereiro de 2020 , para definir os serviços públicos e as atividades essenciais. Diário Oficial da União. 21/03/2020; Edição: 55-H; Seção: 1 - Extra.

Consumer Tecnologia. (2017). Programa Consumer - Vantagens e Desvantagens de Utilizar os Aplicativos de Delivery Online no seu Restaurante. http://www.programaconsumer.com.br/blog/vantagens-e-desvantagens-de-utilizar-os-aplicativos-de-delivery-online-no-seu-restaurantes

Geraldo, G. C., \& Mainardes, E. W. (2017). Estudo Sobre os Fatores que Afetam a Intenção de Compras online. Revista de Gestão, 24 (2), $181-194$.

Gil, A. C. (2019). Como elaborar projetos de pesquisa. (6ºd.): São Paulo.

IBGE. (2020). Instituro Brasileiro de Geografia e Estatística. https://cidades.ibge.gov.br/brasil/sp/piracicaba.panorama

Iodice, G. (2019). Conheça o bilionário mercado de entregas de comida. Revista Forbes, Caderno de Negócios, 20 julho de 2019. https://forbes.com.br/negocios/2019/06/conheca-o-bilionario-mercado-de-entregas-de-comida/

Lemos, F., \& Goes, L. F. (2015). Avaliação do comportamento de consumidores no processo de decisão de compra no M-Commerce e no E-Commerce. XI Brazilian Symposium on Information System, Goiânia, GO, maio, 26-29.

Marconi, M. A., \& Lakatos, E. M. Fundamentos de metodologia científica. (5ª ed.): Atlas 2003.

Marino, R. (2020). Startup Exit: A trajetória de crescimento do Ifood. Blog.eqseed. Seção Investidores, abril de 2020. https://blog.eqseed.com/startup-exitifood/\#: :text=O\%20Ifood\%20atingiu\%20a\%20marca,delivery\%20de\%20refei\%C3\%A7\%C3\%B5es\%20no\%20Brasil.

Matos, S., \& Miranda, L. (2020). Em Foco IBRE: Cenários para o crescimento para o PIB do Brasil em 2020. IBRE. Boletim Macro, março, 2020.

Máximo, W. (2020). Brasil registra retração de 331,9 mil postos de trabalho em maio. Agência Brasil. EBC: Brasília, 29 de junho de 2020. https://agenciabrasil.ebc.com.br/economia/noticia/2020-06/brasil-registra-retracao-de-3319-mil-postos-de-trabalho-em-maio

Montenegro, M. R. (2020). Do Capitalismo de Plataforma à Difusão dos Aplicativos: Apontamentos Sobre Novos Nexos Entre os Circuitos da Economia Urbana em Tempos de Covid-19. São Paulo: Revista Brasileira de Geografia Econômica https://doi.org/10.4000/espacoeconomia.17256

Pereira A. S., et al. (2018). Metodologia da Pesquisa Científica. (1 ${ }^{\mathrm{a}} \quad$ ed.): $\quad$ UFSM, https://repositorio.ufsm.br/bitstream/handle/1/15824/Lic_Computacao_Metodologia-Pesquisa-Cientifica.pdf?sequence=1

Rezende, L. F. M., Thome B., Schveitzer M. C., Souza-Júnior, P. R. B., \& Szwarcwald C. L. (2020). Adults at High-risk of Severe Coronavirus Disease-2019 (Covid-19) in Brazil. Rev Saude Pública, 54 (50).

SEBRAE. (2005). Sebrae Santa Catarina - Delivery para toda ocasião. http://www.sebrae-sc.com.br/leis/default.asp?vcdtexto=4422\&\%5E\%5E

Severino, A. J. (2016). Metodologia do trabalho científico. (24º ed.): São Paulo.

Steendern, M. (2002). Business applications of WAP. The Electronic Library, 20 (3), 215-23.

Torres, C. (2009). A Bíblia do Marketing Digital: Novatec Editora Ltda. 